\title{
Supply and Demand Relationship of Taxi Battery Exchange Based on Big Data: A Case Study of Beijing, China
}

\author{
Zhenhua Gao ${ }^{1}$, Jing Wang $^{2} \&$ Wenrui Ren ${ }^{3}$ \\ ${ }^{1}$ Daxing District Bureau of Economy and Information Technology of Beijing Municipality, Beijing, China \\ ${ }^{2}$ Beijing Best Transport Tech Co., Ltd, Beijing, China \\ ${ }^{3}$ Beijing Transport Institute, Beijing, China \\ Correspondence: Wang Jing, Beijing Beijing Best Transport Tech Co., Ltd, Beijing, 100044, China. E-mail: \\ Wangjingtransport@163.com
}

\author{
Received: March 23, 2021 Accepted: April 28, $2021 \quad$ Online Published: May 7, 2021 \\ doi:10.5539/jms.v11n1p177 URL: https://doi.org/10.5539/jms.v11n1p177
}

\begin{abstract}
The power exchange mode is widely applied in the rental field as an efficient energy supply method for new energy vehicles. The power supply-demand relationship analysis swaps. In particular, the quantitative spatial analysis of sub-regions is of great significance for optimizing the spatial layout of power swapping stations, better operation of taxis, and more efficient power swapping stations. Therefore, this paper analyzes the correlation between the ten states of taxis and the corresponding power exchange. The present analysis targets the limitations in the existing methods to analyze the power exchange supply and demand and utilizing the big data pertaining to real-time taxi operation, order-taking mode, and station-swapping operation. As per the correlations, a calculation method is established to determine the power exchange demand based on the location where the orders are received and the matching method of the power exchange supply and demand. Besides verifying the scientific nature and feasibility of the method empirically, this study also ensured its great flexibility, which allows it to adapt to more complicated social scenarios. The big data analysis indicates that determining the spatial distribution of demand based on the location from where the taxi orders are received is far more rational and practical. Thus, this study has a vital role in guiding the location and layout of interchange stations.
\end{abstract}

Keywords: swap taxi, supply-demand relationship of power swaps, quantitative analysis, spatial layout optimization

\section{Introduction}

The transportation sector has a significant influence on the plans to achieve carbon neutrality. The promotion and application of electric vehicles have been identified as an effective means to achieve this goal. As a fundamental energy replenishment method for automobiles, the battery replacement mode's superiority has been demonstrated in various aspects, including highly efficient energy recharge, reduced costs in an initial car purchase, lesser occupation of land resources, longer battery life, and lesser grid load. Therefore, the evidence proves the strong applicability of this model in rental and other fields. Operations to explore the power swapping mode of electric taxis are already underway in large cities such as Beijing and Xiamen.

Existing literature on the supply-demand relationship of battery replacement emphasizes the theoretical discussion regarding charging and switching modes and spatial layout (He et al., 2021). Moreover, some studies that explore the benefits and costs of the supply-demand relationship of battery exchange adopt a traditional classic model or the improved classic model (Zhou et al., 2013). Regardless, existing studies have the following shortcomings. Firstly, most studies are limited to theoretical results and lack supporting empirical evidence, leading to weaker policy guidance in the analysis of the supply and demand relationship of battery replacement and the optimization of the spatial layout of the battery exchange. Secondly, the existing forecasting models deviate from social reality. Consequently, it is impossible to form an effective spatial layout of the battery replacement supply and demand. For instance, the vehicle scale prediction based on the Bass model does consider the reality that the rental field is franchised by the government, which results in a low correlation between the total scale of taxis and the replacement of petrol-engine vehicles with new energy vehicles (NEVs). 
Furthermore, since this model does not consider factors such as the traffic conditions, construction costs, and regional requirements of the existing parking lot for the construction of the power station, precise site selection or layout optimization based on the cuckoo algorithm or particle swarm algorithm is not achievable.

This research aims to explore the association between supply and demand of car rental and battery swapping based on the big data analysis of taxi operation and power recharging stations. In particular, this study prioritizes three research tasks. The first clarifies the behavioral characteristics of taxi operation and power swapping and determining the general method of quantitative matching of power swap supply and demand. Secondly, this study defines the reasonable range of power swap services and determines the calculation method of battery replacement demand based on the number of orders in one demarcated area. Thirdly, this study uses Beijing as a case to verify the feasibility and practicability of the matching method of battery replacement supply and demand according to the development of taxi battery exchange. The contributions of this paper are twofold. First, besides the theoretical analysis, this study also employs empirical data to verify the theoretical discussions and models. Therefore, the research conclusions are practically applicable in various social situations. Second, the proposed model has strong flexibility. So, it can adapt to more social realities, and it can accurately determine the scope of reasonable power swapping services to establish the accurate location of taxi swap stations.

The remainder of this study is organized as follows. Section 2 contains the literature review. Section 3 presents the methodology, including case, data, and method. The data basis of this paper is clarified through the introduction of data sources. Next, the fundamental issues in big data analysis methods are analyzed, which defines the association between taxi operating status and power replacement demand and determines the quantitative analysis method of power replacement supply and demand relationship. The fourth section analyses the results. Lastly, the fifth section presents the conclusions, and here, Beijing's strategy for battery replacement station construction from 2021-2035 is discussed, and the primary contributions and limitations of this research are summarized.

\section{Literature Review}

In general, the charging and swapping modes of electric vehicles are classified under ordinary charging and swapping, namely full-vehicle charging modes and "centralized charging + swapping" modes. Nonetheless, the fast-charging mode shortens the battery life of electric vehicles. The battery fails to guarantee sufficient operating frequency of taxis and buses. Moreover, a full-vehicle charging mode can generate significant harmonics, which harms the urban public grid and other users. Therefore, the "centralized charging + replacement" model is more practical.

Studies investigating the spatial location for battery changing stations have not explored the supply-demand association. The mainstream methods are based on geographic information distribution, graph theory, etc. These methods aim to select the site that can provide the most services. Specifically, the existing research methods primarily entail mathematical evaluation, prediction models, and geographic information optimization models. The mathematical evaluation prediction model evaluates all candidate stations to select the site with the least cost. For instance, Gan et al. (2019) determined the capacity planning of a charging station with the goal of minimizing the annual construction and operation cost under the "centralized charging + replacement" model. It was concluded that the centralized charging station should be established in the transportation network and the power network, and that the model solution should aim to minimize construction and power line costs to determine the site and capacity of the charging stations. Moreover, Fachrizal et al. (2020) established a two-tier model that considered the construction and operation costs of electric vehicle battery charging stations and the effects of peak-shaving and valley-filling under the "centralized charging + replacement" mode to obtain the optimal planning of the location of centralized charging stations. Furthermore, Wang et al. (2015) proposed a charging and swapping network model based on centralized "charging stations + swapping" stations. This model aims to achieve the shortest total weighted distance between battery swapping stations and the lowest cost of construction, operation, and maintenance of charging and swapping facilities. Upon considering all the above-mentioned factors, the location of the battery replacement stations is determined. The chosen optimal location should ensure that the construction, operation, and maintenance costs of the charging station are minimized under the premise of covering all the needs of the replacement stations. The minimum sum of network loss, construction cost, and operating cost is used as the objective function to determine the optimal sites of switching stations (Ziari et al., 2012). Existing literature on the supply-demand relationship is based on geographic information distribution, graph theory, and other methods to select the site that offers the most services.

From the users' perspective, Ziari et al. (2012) described the driving strategy adopted by these users according to 
different battery SOC. The authors studied the impact of location and quantity of electric vehicle swapping stations on electric vehicle driving distance in three regions across Australia. Accordingly, when the number of battery recharging stations exceeded 40 , the increase in swap stations did not increase the number of kilometers electric vehicles serve. Gan et al. (2019) aimed to minimize the distance between the charging station and the locations where vehicles lack power. The author used the Voronoi diagram to divide the area and optimize the station located in each block before employing the clustering method to adjust the site until a more suitable charging station site is selected. Yang's solution is fundamentally founded upon the idea of a two-stage integer programming model based on scenarios. Using the charging demand data of electric taxis, an electric taxi charging station location model was developed in combination with the power state and space-time network. The model was improved further using the Benders algorithm to select the best location. Ultimately, a scenario-based two-stage integer planning location model for electric taxi charging stations was established. A multi-dimensional power state in a spatial-temporal network is used to define the entire charging demand process. The application of the Benders algorithm to solve the multi-scenario-based location model is also extended. In general, most of the work is limited to simulation or theoretical level and is not realistic.

\section{Methodology}

\subsection{Study Area}

Since July 2019, Beijing municipality began promoting battery swapping taxis through charging and swapping compatible models. The primary form of energy supply is swapping batteries with a minority of vehicles that can be charged under certain special circumstances. By late 2020, the renewed and newly added taxis with compatible charging and swapping modes in Beijing reached 10,500 accumulatively. Moreover, a total of 143 battery swap stations have been constructed, and these adopt the mode of on-site charging and swapping. These figures indicate that Beijing is a typical case in battery recharging stations. Also, charging-swapping-integrated vehicles have been central in the application. Table 1 shows the technical parameters of the vehicle. In this city, a total of 143 replacement stations, including 3.0, 3.0+, and 4.0 models have been established. Table 2 shows the technical parameters.

Table 1. Main technical parameters of the Battery Changing Vehicle

\begin{tabular}{ll}
\hline Model & Battery Changing Version EU300 \\
\hline Driving range of pure battery energy under working condition method $(\mathrm{km})$ & 321 \\
Vehicle charge $(\mathrm{kwh})$ & 47.6 \\
Mass and energy density of power battery system $(\mathrm{Wh} / \mathrm{kg})$ & 146.5 \\
Mass of the whole vehicle $(\mathrm{kg})$ & 1593 \\
Power consumption per hundred kilometer under working conditions $(\mathrm{kwh})$ & 15.1 \\
\hline
\end{tabular}

Table 2. Main technical parameters of the Battery Recharging Station

\begin{tabular}{llll}
\hline Model of the Battery Recharging Station & V 3.0 & V $3.0+$ & V4.0 \\
\hline Number of battery charging bays & 28 & 28 & 60 \\
Operation time of switching a battery & $90 \mathrm{~s}$ & $90 \mathrm{~s}$ & $20 \mathrm{~s}$ \\
Battery replacement time & $5 \mathrm{~min}$ & $3.5 \mathrm{~min}$ & $1.5 \mathrm{~min}$ \\
Number of vehicles Served & $288 / 24 \mathrm{~h}$ & $420 / 24 \mathrm{~h}$ & $960 / 24 \mathrm{~h}$ \\
Charging time & $140 \mathrm{~min}$ & $96 \mathrm{~min}$ & $96 \mathrm{~min}$ \\
Equipment area & $133 \sim 200 \mathrm{~m}^{2}$ & $133 \sim 200 \mathrm{~m}^{2}$ & $175 \mathrm{~m}^{2}$ \\
Power demand & $560 \mathrm{KVA}$ & $960 \mathrm{KVA}$ & $2000 \mathrm{KVA}$ \\
Charger power/load current & $20 \mathrm{kw}$ & $40 \mathrm{kw}$ & $40 \mathrm{kw}$ \\
Number of stations & 84 & 47 & 12 \\
\hline
\end{tabular}

\subsection{Data}

Real-time GPS data of taxi operation in Beijing (positioning per 30 seconds), the operational data of Beijing taxi orders, and the operational data of battery replacement stations in Beijing are the main data sources. The main data fields are shown in Tables 3, 4 and 5, respectively. The three types of data can be correlated and analyzed through the plate number. 
Table 3. Main parameters of GPS data for real-time operation of taxis in Beijing

\begin{tabular}{lll}
\hline Field & Data types & Samples \\
\hline Plate number & Varchar2 & Jing-BD16009 \\
Receiving time & Data & $2020-02-1023: 21: 28$ \\
Starting time & Data & $2020-02-1023: 16: 17$ \\
Total mileage & Data & 46407.0 \\
Real-time vehicle Speed & Data & 44.49 \\
Longitude & Data & 116.41791775142933 \\
Latitude & Data & 40.003528023413075 \\
Soc (Battery Electric Vehicle Only) & Number & 50 \\
\hline
\end{tabular}

Table 4. Main parameters of Beijing taxi order operation data

\begin{tabular}{lll}
\hline Field & Data type & Samples \\
\hline Order number & Varchar2 & 11100198100207011179 \\
Plate number & Varchar2 & Beijing BD16009 \\
Date & Data & $2020-11-13$ \\
Period & Data & $14: 36-14: 52$ \\
Waiting time & Data & $00: 02: 41$ \\
Milage & Data & 9.3 \\
Unit price & Data & 2.3 \\
Amount & Number & 29.1 \\
\hline
\end{tabular}

Table 5. Main parameters of the operation data of the battery replacement stations in Beijing

\begin{tabular}{lll}
\hline Field & Data Type & Samples \\
\hline Order number & Varchar2 & 0010000164202011132359462 \\
Transaction completion Date & Data & $2020 / 11 / 13$ \\
Transaction completion Time & Data & $23: 59: 46$ \\
Card number & Data & 0010000164 \\
Plate number & Varchar2 & BeiingBD16009 \\
Battery recharging station Name & Varchar2 & Da Xing Xing Yi Xing D Station \\
Last ODO & Number & 315 \\
This ODO & Number & 477 \\
Driven distance & Number & 162 \\
Payment amount & Number & 56.7 \\
\hline
\end{tabular}

\subsection{Method}

\subsubsection{Analysis on the Method of Determining the Demand of Battery Exchange}

Electrical taxis avoid accepting orders to remote suburbs with inadequate battery replacement stations, especially when the electricity is less than $50 \%$. However, petrol-engine taxis do not face such limitations. Existing battery replacement supply and demand analysis that employs big data primarily draw on the data of charging pile orders. The supply-demand analysis depends on the data of battery replacement station exchange orders. Since the construction cost of the replacement station is much higher than that of charging piles, and since it is concurrently restricted by numerous factors such as electricity, land, and transportation, the overall number of stations with less flexibility is much lower than charging piles. Besides, the analysis method of order data is not highly generalizable. The number of power replacement orders can mirror the spatial distribution of power replacement demand to a certain extent. However, it cannot help guide the site selection and layout of the battery replacement station. The underlying reason is that the quantity of power replacement service orders is highly correlated with the current service capacity and utilization rate of the station. In general, areas that have no power recharging stations have a greater need for stations, yet, it cannot be reflected in the supply-demand relationship. The battery replacement demand through the tension of the supply and demand relationship cannot reflect the actual battery exchange demand. For example, if a large area with a high demand for battery replacement has only one battery replacement station, then the utilization of this battery replacement station is saturated, it can only be stated that there is a demand for new stations in this area. In such a case, there would be little understanding regarding the location to construct the station. Therefore, this method is not practically helpful in site and layout selection. To accurately analyze the demand for battery replacement, the analysis should begin from the status of taxi operation and parking. Details are given in Table 6. 
Table 6. Analysis of taxi status

\begin{tabular}{|c|c|c|c|c|c|c|}
\hline $\begin{array}{l}\text { Status } \\
\text { serial } \\
\text { number }\end{array}$ & Vehicle Status & & Status Description & $\begin{array}{l}\text { Whether there is a } \\
\text { need for battery } \\
\text { replacement }\end{array}$ & $\begin{array}{l}\text { Whether to } \\
\text { replace the } \\
\text { battery or not? }\end{array}$ & $\begin{array}{l}\text { Is the status } \\
\text { identifiable? }\end{array}$ \\
\hline 1 & Operating & Driving & $\begin{array}{l}\text { The status of driving when transporting } \\
\text { passengers from the origin to the } \\
\text { destination }\end{array}$ & Yes & No & Yes \\
\hline 2 & & Parking & $\begin{array}{l}\text { The status of parking and waiting due to } \\
\text { traffic congestion, red lights, etc. }\end{array}$ & Yes & No & Yes \\
\hline 3 & Order-seeking & Driving & $\begin{array}{l}\text { The status of driving when cruising the car } \\
\text { in order to obtain an order }\end{array}$ & Yes & Yes & No \\
\hline 4 & & Parking & $\begin{array}{l}\text { The status of being parked and waiting at a } \\
\text { place in order to get an order or to take a } \\
\text { break }\end{array}$ & Yes & Yes & No \\
\hline 5 & Booking & Driving & $\begin{array}{l}\text { The status of having obtained a reservation } \\
\text { order to go to the named place }\end{array}$ & Yes & No & No \\
\hline 6 & & Parking & $\begin{array}{l}\text { The status of having arrived at the } \\
\text { departure point to wait for passengers }\end{array}$ & Yes & No & No \\
\hline 7 & $\begin{array}{l}\text { Battery } \\
\text { changing }\end{array}$ & Driving & $\begin{array}{l}\text { The status of waiting in line for the battery } \\
\text { replacement in the power exchange station }\end{array}$ & Yes & Yes & No \\
\hline 8 & & Parking & $\begin{array}{l}\text { The status of parking at the operating floor } \\
\text { during the changeover process }\end{array}$ & Yes & - & Yes \\
\hline 9 & Non-operating & Driving & $\begin{array}{l}\text { The status of driving during off work time } \\
\text { or shift changeover }\end{array}$ & Yes & Yes & No \\
\hline 10 & & Parking & $\begin{array}{l}\text { The status of parking during non-operating } \\
\text { hours }\end{array}$ & No & No & No \\
\hline
\end{tabular}

There are 10 states of taxis, except state 10, all others have battery replacement demands. According to the questionnaire on the willingness to exchange battery of 1,000 taxi drivers, $73 \%$ of them are habituated to changing the battery whenever it runs out. A more reasonable layout of the swap station results in shorter scheduling and queueing time for the swap, and the remaining power is sufficient to accept long-distance orders, this ratio could be further increased. Since the battery replacement during the service process greatly reduces the service level of the taxi, the taxi can be recharged only in state 3 , state 4 , state 7 , and state 9 . However, based on the existing data, only state 1 , state 2 , and state 8 are identifiable. So, it is difficult to accurately calculate the power change demand. Overall, status 7 and the current distribution of power swap stations indicate a strong correlation, which primarily reflects the supply and demand relationship of power swap, meanwhile, the correlation between status 9 and home charging is stronger. Therefore, power swap demand analysis should focus on the characteristics of status 3 and 4 . Based on the analysis of taxi status, this study has determined four clues for the spatial distribution of battery replacement demand, as shown in Table 7. Generally, the initial position of the driving state is where the order is received, unless the taxi is in the operational state. The taxi will be as close as possible to the hot area of the order position to accept more orders and higher revenue. Besides, both the order-seeking driving state and the order-seeking parking state relate highly to the order position. Therefore, after comparative analysis, it is determined that using clue one is the most reasonable option to determine the spatial distribution of battery replacement demand.

Table 7. Main clues for calculation of battery replacement demand

\begin{tabular}{|c|c|c|c|c|}
\hline Main clues & Clue one & Clue two & Clue three & Clue four \\
\hline Clue description & $\begin{array}{l}\text { Spatial distribution data based } \\
\text { on locations where orders are } \\
\text { received }\end{array}$ & $\begin{array}{l}\text { Spatial distribution data } \\
\text { based on locations where } \\
\text { passengers get off }\end{array}$ & $\begin{array}{l}\text { Spatial distribution } \\
\text { data based on all GPS } \\
\text { positions of taxis }\end{array}$ & $\begin{array}{l}\text { Spatial distribution data based } \\
\text { on the parking position of the } \\
\text { taxi for a certain period }\end{array}$ \\
\hline $\begin{array}{l}\text { Correlation with } \\
\text { taxi status }\end{array}$ & $\begin{array}{l}\text { Can indirectly reflect the } \\
\text { comprehensive characteristics } \\
\text { of state } 3 \text { and state } 4\end{array}$ & $\begin{array}{l}\text { Cannot distinguish status } 3 \text {, } \\
4,5,6,7,9\end{array}$ & $\begin{array}{l}\text { Cannot distinguish } \\
\text { states other than state } \\
10\end{array}$ & $\begin{array}{l}\text { Cannot reflect status } 3 \text {, cannot } \\
\text { distinguish status } 2,4,6\end{array}$ \\
\hline $\begin{array}{l}\text { Workload of data } \\
\text { analysis }\end{array}$ & moderate & Moderate & Heavy & Heavy \\
\hline
\end{tabular}




\subsubsection{Matching Method Analysis of the Power Exchange Supply and Demand}

Unlike private cars, taxis, as operating vehicles, should have quick access to an energy supply through power exchange to improve operational efficiency. The comprehensive energy supply efficiency of power exchange service depends on the power exchange rate and the distance between taxis and the nearest power exchange station. Therefore, taxis are expected to obtain the power exchange service in the nearest areas. The necessary infrastructure for power swapping stations must have advanced and forward-looking planning and construction to promote electric taxis. Given the operation of the power station, if the service scope of the power station is too small, the power changing station's service capacity cannot be utilized effectively. Under such circumstances, the profits cannot cover the construction and operational costs. Therefore, the construction and operation parties expect each power station to provide services for more vehicles to enhance operational benefits. Overall, a holistic approach is needed to reconsider the comprehensive operational needs for taxis and power stations. Besides, to reasonably determine the scope of power exchange service, numerous other conditions should also be considered, such as the urban road network density, traffic flow, parking density, land cost, and power conditions.

The rasterized analysis is a conventional spatial analysis method, it contains advantages such as clear boundary, easy calculation, and full domain coverage compared with the coverage analysis methods, including circle coverage. Approximately determining the association between supply and demand and reserving a reasonable space for the location of the exchange stations can reduce the amount of data calculations. As such, the rasterization method provides a reasonable approximation of the service range of the exchange stations. Another assumption is that the exchange station in a certain raster only provides service to the cabs in that particular raster. Moreover, the cabs with the demand for electricity exchange in a certain raster only gets service from the raster it is in.

$\mathrm{C}_{\mathrm{j}}$ - Designed service capacity of the $\mathrm{j}$-type exchange station

$\mathrm{F}_{\mathrm{i}}$-Average daily number of orders received by cabs in the i-th grid

$\mathrm{F}_{\mathrm{A}}$-Average daily number of orders received by all cabs

$\mathrm{E}_{\mathrm{A}}$ - The average number of daily exchanges of all cabs

$\mathrm{Q}_{\mathrm{ij}}$-The current number of $\mathrm{j}$-type power exchange stations in the $\mathrm{i}$-th grid

$\mathrm{DS}_{\mathrm{i}}$ - The demand difference of the number of power exchange in the $\mathrm{i}$-th grid

$$
\mathrm{DS}_{\mathrm{i}}=\mathrm{F}_{\mathrm{i}} \frac{\mathrm{E}_{\mathrm{A}}}{\mathrm{F}_{\mathrm{A}}}-\sum_{\mathrm{j}=1}^{\mathrm{n}} \mathrm{C}_{\mathrm{j}} \times \mathrm{Q}_{\mathrm{ij}}
$$

Since the cab industry is government-licensed, the scale of vehicles is limited to some extent. More specifically, vehicles are mainly replaced by petrol-engine cabs. To explore the supply and demand of power exchange stations, it is important to consider the operational characteristics of fuel cabs to avoid carrying excessive impact on the normal operation of cabs due to the supply of power exchange services.

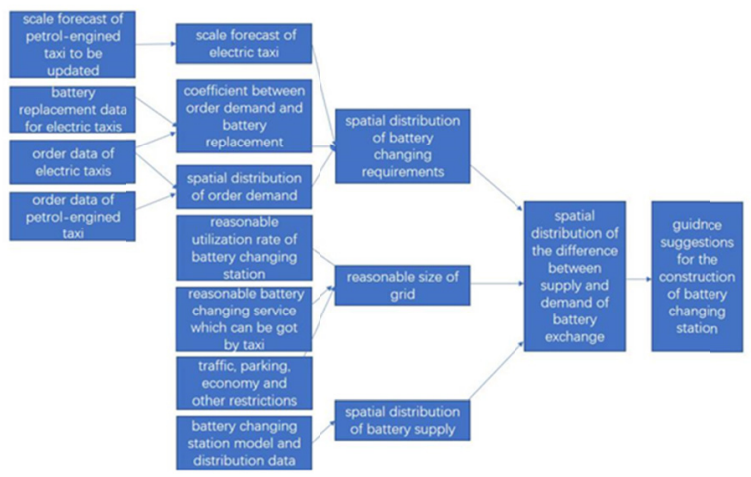

Figure 1. The matching method of the power exchange supply and demand

\section{Results}

Based on the big data analysis of the regular power exchange operation, this study collected the data of power 
exchange stations from August 17th, to August 23rd in the summer and from 23rd November to 29th November in the winter of 2020. It was found that the average daily number of power exchange of each cab in winter was 2.3 times, while in summer it was 1.8 times, indicating obvious seasonality. Details are given in Figures 1 and 2 . To ensure that cabs can get qualified service of power exchange, this study utilizes the data of power exchange in winter for detailed analysis. The average daily number of order pickups for power exchange cabs and fuel cabs from November 23rd to 29th, in 2020 is 11.4 times and 11.7 times, respectively. In calculating the number of order pickups for power exchange cabs, the conversion factor of the number of received orders and the number of power exchanges $=$ average daily number of order pickups/average daily number of power exchanges. Figures 4 and 5 show the spatial distribution of receiving orders in some typical periods for both power-exchange cabs and fuel cabs, where the sides of the grid are $1 \mathrm{~km}$ and the values in the grid denote the number of pickups in the grid.

Based on the calculation of reasonable cab operation service level and power exchange station operation, combined with Beijing's road network structure, traffic congestion, public parking lot distribution, and other factors, the contribution to match the reasonable grid side length is $5 \mathrm{~km}$. Under the relevant policy requirements, from 2021 to 2025, fuel cabs in Beijing will be updated to pure electric cabs and charging and exchanging models, and power exchanges will become mainstream. By 2025, the number of electric replacement vehicles is estimated to reach 62,000 , and the demand for electric replacement in winter is expected to reach 143,000 times/day. The spatial distribution of the demand for electric replacement in 2025 shown in Figure 8 is obtained by considering the spatial distribution in the average daily number of orders received by electric replacement cabs and fuel cabs from November 13th, 2020 to November 26th, 2020 as the weighting factor.

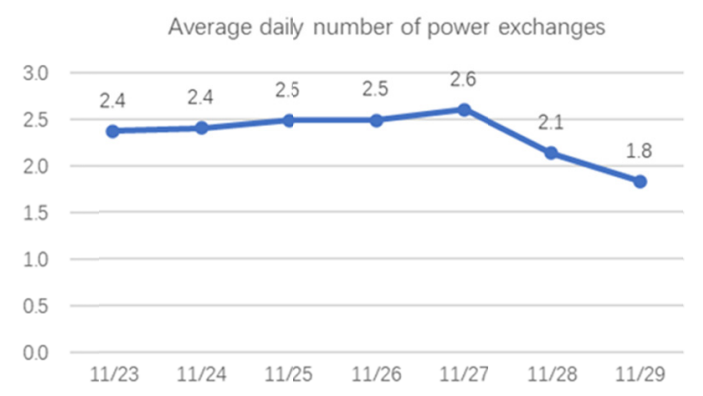

Figure 2. Distribution of the average daily number of power exchanges of cabs from 23rd November, 2020 to 29th November, 2020

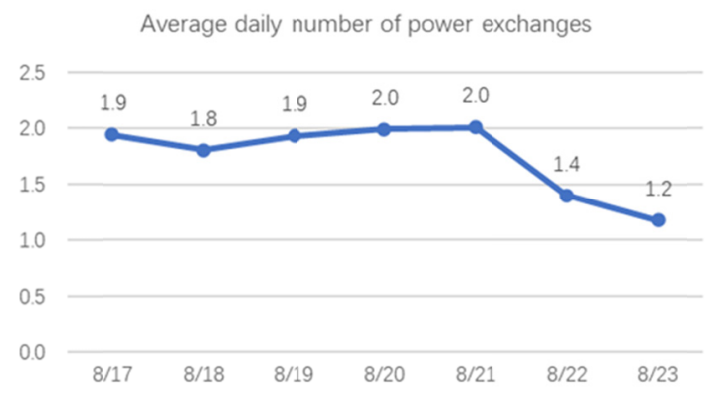

Figure 3. Distribution of the average daily number of power exchange cabs from 17th August, 2020 to 23rd August, 2020 


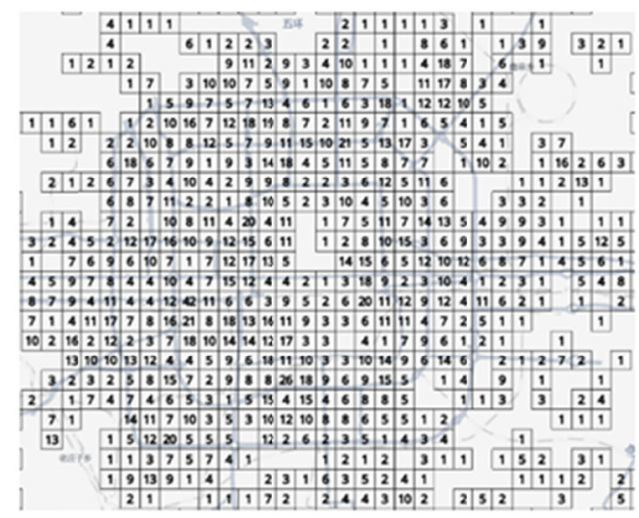

Figure 4. Distribution of the space of the connection unit of the cab exchange 11.26.7 - 11.26.9

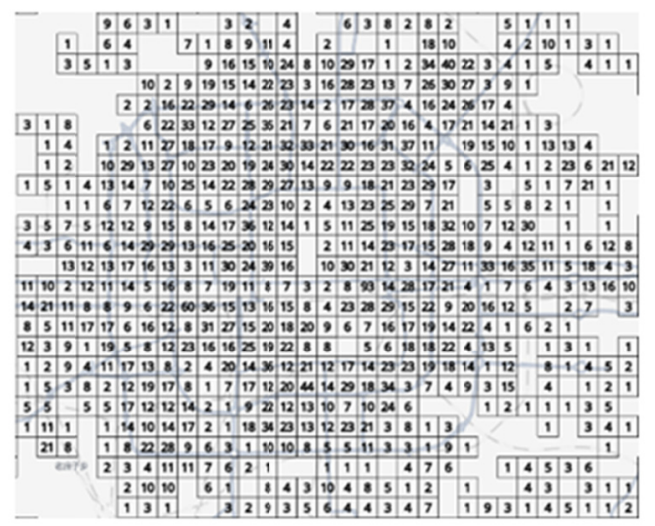

Figure 5. Fuel cabs 11.26.7 -11.26.9 Pickup unit placement space distribution

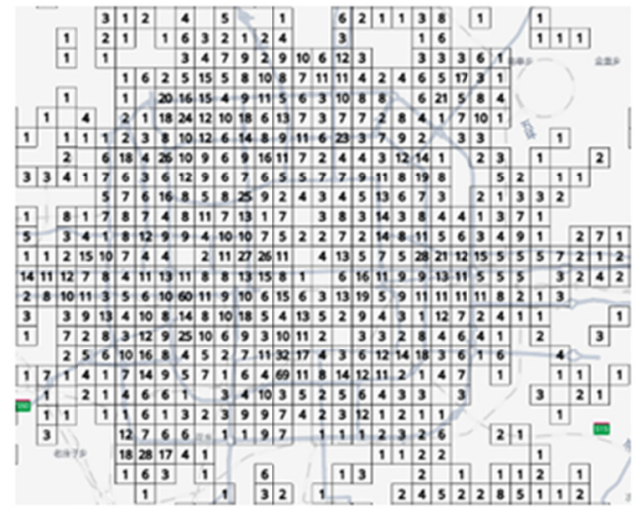

Figure 6. Switching cab 11.26.17-11.26.19 pick-up unit placement space distribution 


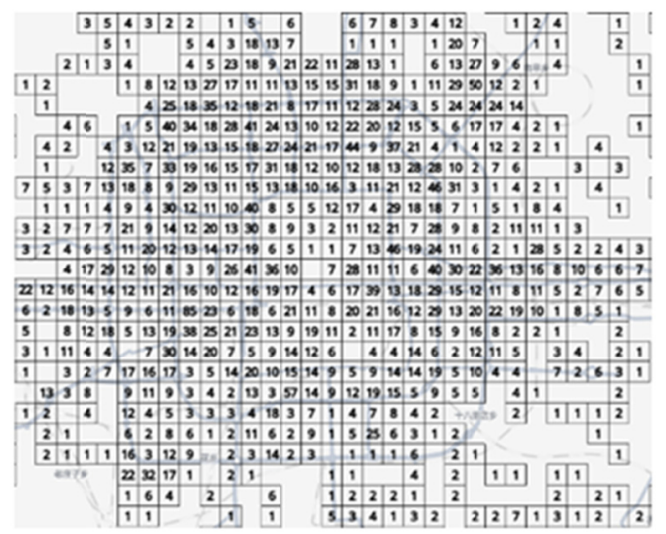

Figure 7. Fuel cab 11.26.17-11.26.19 pickup unit placement space distribution

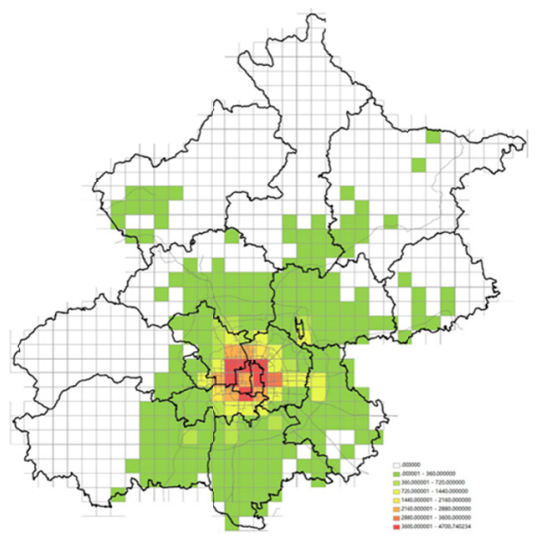

Figure 8. Spatial distribution of power exchange demand (number of times) in 2025

According to the service capacity and weighting ratio of the existing V3.0, V3.0+, and V4.0, the average service capacity of the exchange station is determined to be 388 times/day. Figure 9 is the output from the demand supply difference analysis. From 2021 to 2025, the exchange station construction gap is primarily concentrated in the northwestern area of the central city, with the largest gap between the West Second Ring Road and the West Fourth Ring Road, while the Xicheng District, the southern part of Haidian District, a large gap still exists in the Olympic Park area, and these areas should be focused in the next construction phase.

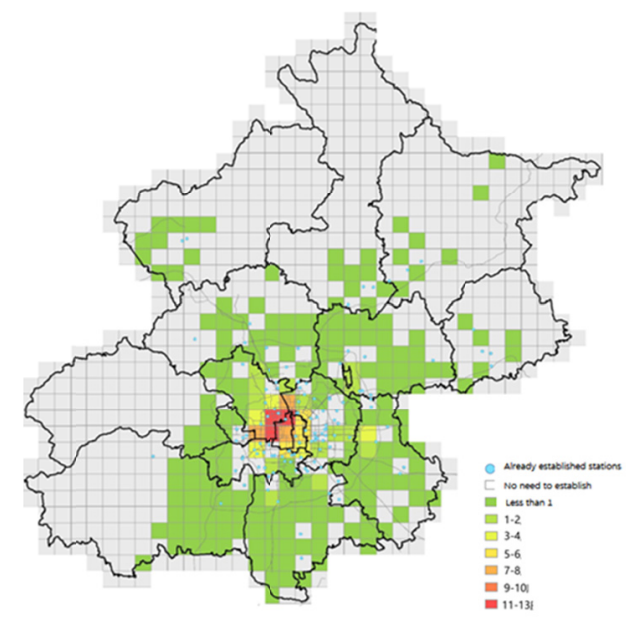

Figure 9. Spatial distribution of the gap in the number of swapping stations 


\section{Conclusion}

This paper analyzes the problems of overly theoretical, imprecise and inaccurate demand quantification in the current analysis of power exchange supply-demand relationship, relying on the real-time GPS of Beijing, the number of received orders and power exchange operation. It proposes the idea and method of calculating the spatial distribution of power exchange demand based on the spatial distribution data of the location of order receiving moments. At the same time, a raster analysis method is used to determine the reasonable service area of power exchange stations and use it as a unit of analysis to realize the quantitative analysis of power exchange supply and demand relationship. Finally, the paper demonstrates the feasibility of the method through the example analysis of Beijing, and proposes the key areas for the construction of power exchange stations in Beijing from 2021 to 2025, and quantifies the demand for the number of stations. This research can help to implement to make policies of balancing the demand and supply of the charging stations of new energy vehicles.

In order to realize the quantitative matching of the power exchange supply and demand relationship, this paper simplifies the consideration of the overall development trend of the cab industry, the charging demand of power exchange cabs, the peak and valley time characteristics of power exchange, and the cost economy of power exchange, so there is still broad room for improvement. It will also be a key direction of the next research.

\section{Acknowledgments}

The authors whould like to delclare that there is no confict of interes.

\section{References}

Fachrizal, R., Shepero, M., van der Meer, D., Munkhammar, J., \& Widén, J. (2020). Smart charging of electric vehicles considering photovoltaic power production and electricity consumption: A review. eTransportation, 4, 100056. https://doi.org/10.1016/j.etran.2020.100056

Gan, H., Zheng, C., \& Cui, H. (2019). A two-stage model for capacity planning of centralized charging station and ordered discharging. Journal of Intelligent \& Fuzzy Systems, 37(4), 4837-4846. https://doi.org/10.3233/JIFS-179321

He, L., Ma, G., Qi, W., \& Wang, X. (2021). Charging an electric vehicle-sharing fleet. Manufacturing \& Service Operations Management, 23(2), 471-487. https://doi.org/10.1287/msom.2019.0851

Wang, M., Ismail, M., Shen, X., Serpedin, E., \& Qaraqe, K. (2015). Spatial and temporal online charging/discharging coordination for mobile PEVs. IEEE Wireless Communications, 22(1), 112-121. https://doi.org/10.1109/MWC.2015.7054726

Zhou, L., Li, F., Gu, C., Hu, Z., \& Le Blond, S. (2013). Cost/benefit assessment of a smart distribution system with intelligent electric vehicle charging. IEEE Transactions on Smart Grid, 5(2), 839-847. https://doi.org/10.1109/TSG.2013.2282707

Ziari, I., Ledwich, G., Ghosh, A., \& Platt, G. (2012). Optimal distribution network reinforcement considering load growth, line loss, and reliability. IEEE Transactions on Power Systems, 28(2), 587-597. https://doi.org/10.1109/TPWRS.2012.2211626

\section{Copyrights}

Copyright for this article is retained by the author, with first publication rights granted to the journal.

This is an open-access article distributed under the terms and conditions of the Creative Commons Attribution license (http://creativecommons.org/licenses/by/4.0/). 